\title{
Malay Traditional Food Knowledge Transfer
}

\author{
Mohd Shazali Md. Sharif, Ahmad Esa Abdul Rahman, \\ Mohd Salehuddin Mohd Zahari, Khairunnisa Mohamad Abdullah
}

Faculty of Hotel \& Tourism Management, Universiti Teknologi MARA, 42300 Puncak Alam, Selangor, Malaysia

shazali@salam.uitm.edu.my

\begin{abstract}
This study offers insight into Malay festive cookery and its importance in the transmission of traditional food knowledge among the younger generation. Respondents were observed in four separate ethnographic investigations involving four Malay families. The results indicate that festive cookery plays a significant role for the younger generation to acquire knowledge about traditional food. Thus, it is vital to conserve the practice of preparing the meal for festive occasions to ensure the continuation of traditional culinary culture, customs, and traditions.

Keywords: Festive cookery; Malay ethnic; Knowledge transmission; Malay traditional food

eISSN 2398-4279 @ 2018. The Authors. Published for AMER ABRA cE-Bs by e-International Publishing House, Ltd., UK. This is an open access article under the CC BY-NC-ND license (http://creativecommons.org/licenses/bync-nd/4.0/). Peer-review under responsibility of AMER (Association of Malaysian Environment-Behaviour Researchers), ABRA (Association of Behavioural Researchers on Asians) and cE-Bs (Centre for EnvironmentBehaviour Studies), Faculty of Architecture, Planning \& Surveying, Universiti Teknologi MARA, Malaysia.
\end{abstract}

DOI: https://doi.org/10.21834/ajqol.v3i10.103 


\subsection{Introduction}

Eating habits in Malaysia are changing gradually from traditional to global. The younger Malay generation, for instance, is consuming a wider selection of food not limited to local and traditional foods. The adaptation of western diet and the rise of fast and convenience food consumption are contributing to the decreased appreciation of traditional food among the younger generation. Besides, the deskilling of the younger generation in producing traditional dishes especially festive food is a threat to the continuity of Malay culinary tradition. As an important cultural element, traditional food is a reflection of local identity. Festive foods, in particular, are closely associated with heritage and have various cultural significance. However, the production of Malay festive food is primarily the responsible of the older generation with minimal interest and involvement by the younger generation.

\subsection{Literature Review}

\section{Malay Festive Cookery}

Malay is an ethnic group of Austronesian people who live in Nusantara, which include the Malay Peninsula, East Sumatra, southern Thailand, the southern coast of Burma, Singapore Island, the coast of Borneo, including Brunei, West Kalimantan, Sarawak and Sabah coast and the smaller islands which lie between these locations. (Azri, 2006; Crouch, 1996; Gungwu, 1985; Jaffar, Hussain, \& Ahmad, 1992; Munan, 1990; Rahman, 2011). The Malays, being Muslims, celebrate two major celebrations namely Hari Raya Haji (Eid al-Fitr) and Hari Raya Puasa (Eid al-Adha). The main menu for both celebrations is traditional foods such as rendang, ketupat, lemang and kuah kacang. These specialties require a tremendous amount of time, knowledge and skill to prepare. For instance, rendang needs to be braised over a low fire for a minimum of 2 hours until the meat is tender and the sauce is cooked down to a dry paste consistency. Ketupat is another important traditional festive food. A special knowldege and skill are required to weave banana leaves into casings. The casings are then filled up with rice and boiled in water for four hours. The preparation of festive foods usually starts a day before Hari Raya. Family members would often spend all day in the kitchen to prepare a special feast for the celebration. Festive cookery can be an effective avenue showcase traditional cooking techniques to the younger generation.

\section{Food Knowledge Transfer}

Food knowledge is defined as the oral transmission of knowledge related to the production of food between generations within the community of an ethnic group. (Guerrero et al., 2009; Milburn, 2004; V.Kuhnlein, Donald, Spigelski, Vittrekwa, \& Erasmus, 2009). The transmission modes include observation, word of mouth, and hands-on activities. Children or young adults may also acquire knowledge about food by consuming food prepared by their elderly. Food knowledge can be discovered in numeral ways such as through parents, family and community members, during the social or festive celebration (Kwik, 2008; Trichopoulou, Soukara, \& Vasilopoulou, 2007; Yohannes, 2009). Food knowledge transfer would usually 
refer to the transmission of skills in producing traditional foods that are highly associated with a cultural identity. According to Kwik (2008), food tradition is a reflection of the custom of ethnic culture and sometimes related to religious practices. Food knowledge transfer is essential for the maintenance of food tradition (Ohiokpehai, 2003) and communities and ethnic group is responsible for transmitting food knowledge to the younger generations. The interactions during the process of transferring of knowledge may incur between individuals, groups, and from groups to organization (Wilson, Ward, \& Fischer, 2013). An effective knowledge transfer process would include the application of the knowledge, followed by monitoring and evaluation (Szulanski, 2000).

\section{Food Practice Continuity}

Food practice continuity refers to the application of food knowledge in its purest form without any alteration as time passes. The continuity of traditional food practice practically would involve mother as the transfer mediator and daughter/children as the recipient of knowledge. It is important to note that the contribution of mothers in food knowledge transfer is crucial to ensure a lasting survival of ethnic food traditions and identity (Sharif, Zahari, Nor, and Muhammad, 2013). Children may be exposed to the knowledge of food once they reach adolescence. At this age, children can practice the food knowledge received from their mothers. Food knowledge transfer occurs mainly during school holidays and festive seasons when both mothers and children have sufficient time to spend in the kitchen. It's hard for the transmission to occur on normal days as families are busy with work and school commitments (Chenhall, 2011; Md. Nor et al., 2012; Sharif, Nor, \& Zahari, 2013). To cope with the hectic lifestyle, many families are abandoning the tedious practice of cooking traditional foods. The cooking of traditional foods is reserved mainly for a special occasion and festive celebration. It is important to note that traditional food and culinary traditions disappear simply because they are no longer practices by the community. Today, many traditional foods are at risk of becoming extinct because of the intrusion of foreign food culture and more importantly family recipes not being taught to the younger generation.

\subsection{Methodology}

This study employed participant observation and ethnographic techniques. Data collection process includes picture taking of the preparation of Malay festive foods in conjunction with the celebration of Eid al-Adha (Hari Raya Haji). Ethnographic techniques require the ethnographers to have an up close and personal experience and possible participation (Merriam, 2009). The event was studied in its natural setting to observe conducts including non-verbal communication such as emotions and facial expressions. Participants were interviewed to gain deeper insight into the importance of festive cookery in transmitting food knowledge to the younger generation. A total of four set samples were studied involving four Malay families from Negeri Sembilan, Penang, and Perak. To explore the transmission of traditional Malay festive food knowledge, each sample consists of two generations of the same family (mother and daughter). The older respondents consist of mothers aged between 50 and 60 while younger respondents consist of daughters aged between 20 and 22. Data 
collection were conducted at the respondents' home and wet market during the preparation of the meal for Hari Raya Haji celebration to observe the transmission of traditional food knowledge transfer between the two generations. All preparations were observed, and pictures of all related activities performed were taken for reference.

\subsection{Findings and Discussions}

The results indicate that festive cookery is an important cultural practice in the transmission of traditional food knowledge. It is an avenue for the younger generations to learn and acquire knowledge about traditional foods and skill to prepare them. The learning process began when the respondents accompanied their mothers to the wet market to buy ingredients to be used for cooking Hari Raya. This was the moment where the younger respondents were exposed to various ingredients such as herbs and spices that have been used in preparing traditional Malay festive foods for generations. Subsequently, respondents were guided by their mothers on the techniques to be used to prepare the ingredients, followed by specific cooking methods for each dishes. Results from the observation signify the importance of festive cookery in transmitting traditional food knowledge to the younger generations. Festive cookery is a comprehensive avenue for food knowledge transfer albeit lengthy. The extensive hours spent together by both mothers and daughters in preparing foods for festive celebration is a useful way of passing down family recipes and culinary traditions. Below are important points that indicate the significance of food knowledge transfer via festive cookery:

\section{Provide a Semi-Formal Training to Acquire Malay Culinary Skills.}

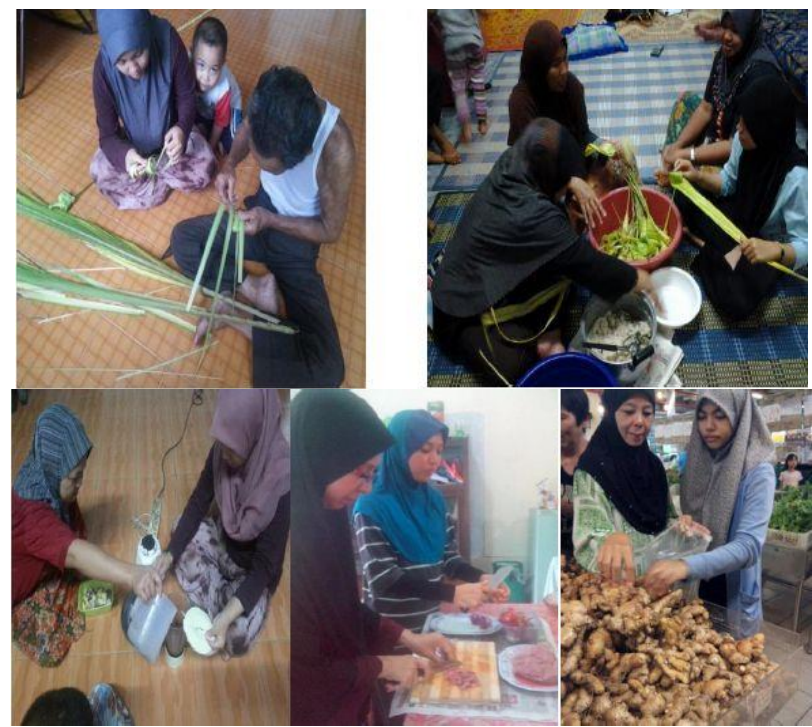

Figure 1: Scenario of food preparation and cooking process for 'Eid Adha 2013. 
Figure 1 exhibits the participation of the younger generations in festive cookery. Tedious preparation such as ketupat casing weaving which requires specific technique and skill was performed under close supervision. There are various types of ketupat casing, and each casing applies different weaving technique. For such a technical process, a mother would work closely with her daughter and provide a continuous guidance and feedback. A festive cookery is an advantageous form of food knowledge transfer. It provides a hands-on experience for the younger generation to develop required culinary skills to produce traditional foods. The younger respondents noted that festive food preparation is an important avenue for them to gain more knowledge about traditional Malay cooking. It is the only time for them to learn culinary technique such as ketupat casing weaving because ketupat is only produced during festive seasons.

\section{Familiarize Younger Generations with Traditional Foods, Culture, and Traditions.}
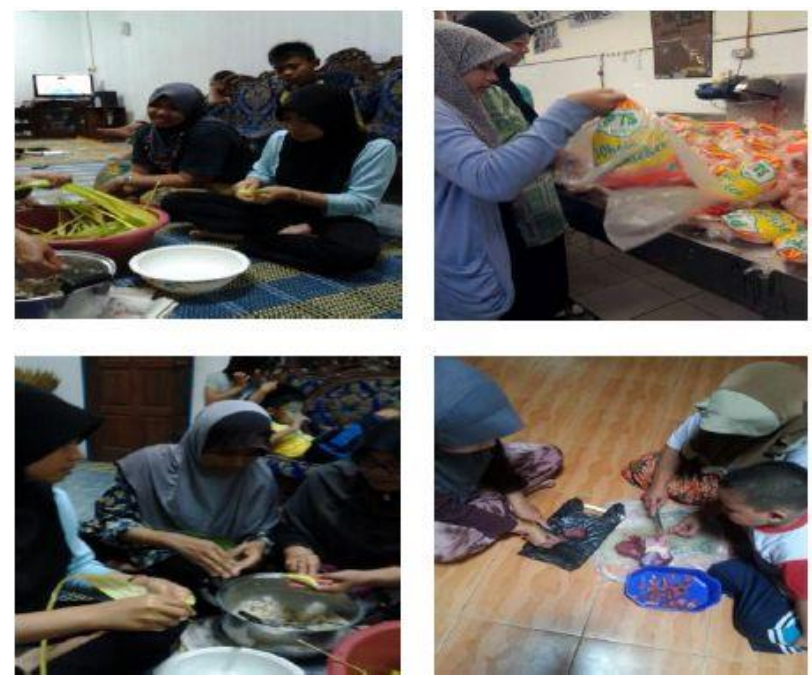

Figure 2: Young generations involvement in festive food preparations.

Figure 2 depicts the involvement of the younger generations in the preparation of foods for Hari Raya. Teenagers are expected to help their parents with food preparation as a way of transmitting traditional food knowledge. It was observed that the younger children were less helpful but were inquisitive. They asked various questions regarding ingredients and the overall preparation of foods. The results demonstrate that festive cookery provides an opportunity for the younger generations to learn various aspects of Malay culinary culture. The interaction between older and younger generations during the preparation is effective in transmitting traditional food knowledge and skill. All younger respondents agreed that festive cookery allowed them to have a deeper insight into Malay food culture and higher appreciation of their culinary customs and traditions. 
Facilitate knowledge transfer of ingredients, preparation and cooking techniques used in Malay cuisine.
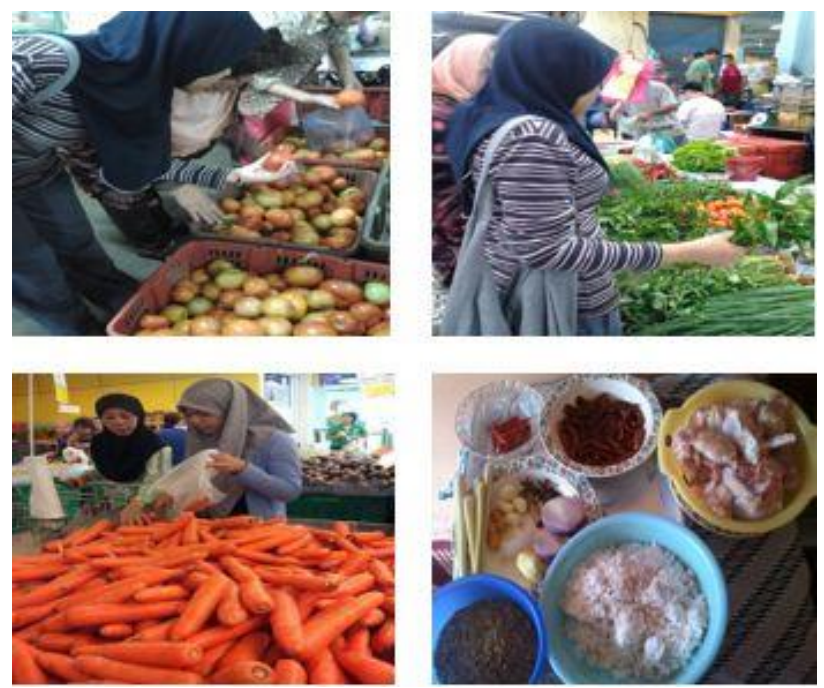

Figure 3: Buying and selecting ingredients for festive cookery at the wet market and preparation of ingredients for cooking.

Figure 3 portrays the early form of food knowledge transfer happening during a visitation to a wet market. The younger generations are encouraged to assist their parents in purchasing ingredients to be used for the preparation of Hari Raya food. The event would usually take place a few days before the festive cookery. The observations show that daughters were guided by their mothers in the selection of ingredients as a way to expose the younger generations to the various types of native produce common to Malay cuisine. One mother participant mentioned that it was important to ensure the involvement of the younger generation in the selection and purchasing of cooking ingredients because these processes will determine the quality and flavour of the food cooked. The process of food knowledge transfer continued in the kitchen when the ingredients were processed and prepared for cooking. It involves basic culinary techniques such as cutting, grinding, and more. All younger participants noted that the preparation process gave them a chance to understand better the function of each ingredient in Malay cookery and the correct technique of handling each unique ingredient.

\section{Ensure Continuous Appreciation, Production, and Consumption of Malay Traditional Foods.}

Pictures of traditional Malay festive foods above (Figure 4) were taken from a different family sample. The image on the top left shows ketupat daun palas (steamed glutinous rice cooked with coconut milk wrapped in palm leaves) and ketupat nasi (rice boiled in young coconut 
leaves casing) on the top right. Both starches are staples during Hari Raya and consumed with dishes such as rendang and kuah lodeh as shown in the other two images. Respondents indicated that festive cookery is important because many Hari Raya foods are signature dishes that reflect the identity of the Malays. Therefore, it is important to include the younger generation in festive food preparation. Early exposure will ensure continuous appreciation, production, and consumption of Malay traditional food. The serving of traditional food during festive season provide an opportunity for the younger generation to experience local culinary fares and instil a fondness for local flavours.
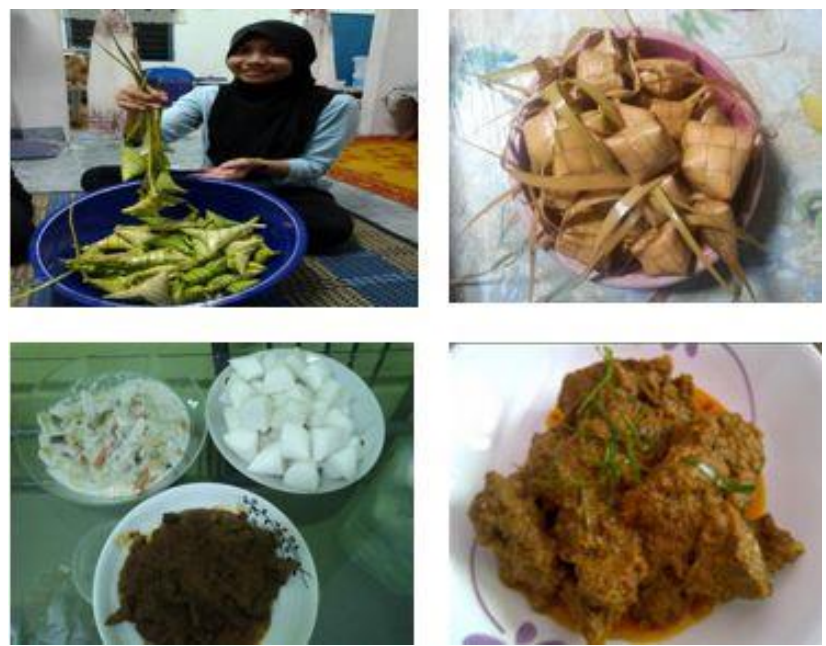

Figure 4: Traditional Malay foods served during Hari Raya

As an important cultural element, Malay traditional food is a reflection of the community's character and sense of place. Malay festive foods are signature cultural elements that symbolize the historical background of the Malay society, thus ensuring its continuity is vital. However, the decreased appreciation and deskilling of the younger generations in preparing traditional foods is alarming. The increased consumption of foreign food by the younger generations shows that they are gradually straying away from a traditional diet. To promote a greater appreciation of Malay traditional food amongst younger generations, it is crucial to involve children, teenagers, and young adult in meal preparation. This study indicates that festive cookery has a significant importance in the transmission of traditional food knowledge. For instance, interactions between mothers and daughters during the preparation of foods allow the younger generation to acquire Malay culinary skill and knowledge about traditional foods and its cultural importance. The preparation of a meal for Hari Raya celebration acts as a semi-formal avenue that can facilitate the younger generations to develop traditional culinary skill and knowledge. The older generation especially mothers is culinary teachers that are effectual in passing down family recipes and culinary traditions. Festive cookery allows the younger generation to familiarize with Malay traditional ingredients, foods, culture 
and traditions. Their involvement in the various stages of festive cookery such ass selection and purchasing of cooking ingredients, preparation and cooking of meal ensure continuous appreciation, production, and consumption of Malay traditional foods. Therefore, mothers are encouraged to prepare a home cooked meal for the festive celebration. Festive cookery provides an opportunity for the younger generations to learn and develop culinary skills to produce traditional foods. Children should be encouraged to participate in festive cookery to instill interest in local food culture and traditions and eventually continuous appreciation of Malay culinary heritages.

Malay traditional foods symbolize Malay culture and thus its continuity is very crucial. Transmission of Malay traditional food knowledge is valuable in integrating bonding in the family as well as serves as family's cultural bridge (Kwik, 2008). Even though young generations nowadays are more exposed to modern foods such as fast foods and convenience foods, they need to aware the importance of continuity of Malay traditional foods. Knowledge transmission on Malay traditional foods usually occurs between mothers and daughters. It will be more effective when both the mothers and daughters involve two ways communication during the process. Besides, the mothers also need to let the daughters do some works during the process on their own. This will build confidence in the daughters to prepare the food alone next time. It is also proven that by involving the daughters in the whole process starting from going to the wet market to recognize and purchase the ingredients for the cooking process, will make the knowledge transfer more effective. From this research, it is known that food preparation process during festivals that involve more people will also help in knowledge transmission among the daughters (Sharif, Nor, et al., 2013). Although, young generations always claim that they do not have enough time to prepare and cook Malay traditional foods due to hectic working life, but they still love to eat foods that taste like their mothers' cooking (Md. Nor et al., 2012; Sharif, Zahari, et al., 2013). Thus, most of the mothers believe that transmission of knowledge of Malay traditional foods to their children especially the daughters as early as adolescent age is very important for the continuity of Malay traditional foods. The mothers believe that children need to be guided in preparation and cooking process, and they need to be given chances to prepare them by themselves. However, young generations themselves also need to have an effort to learn and conserve the Malay traditional foods.

\subsection{Conclusion}

Overall, traditional food knowledge transfer is critical for the survival of Malay culinary heritage. The findings indicate that festive cookery is an important event for the younger generations to learn and acquire culinary skills to produce Malay traditional food. Interactions between older and younger generations during the preparation of the meal for Hari Raya celebration can induce interest in appreciating Malay culinary heritage. This study suggests that home cooking should be practiced in every household. For busy families, occasional cooking like festive cookery is an important tool to ensure the survival of traditional food. It is suggested that further studies should be conducted to explore the ability of the younger generation to reproduce traditional food learned without adult supervision. The result will 
further validate the effectiveness of festive cookery as an avenue for tradition food knowledge transfer.

\section{Acknowledgement}

This research was funded by the Ministry of Higher Education, Malaysia through Universiti Teknologi MARA under RAGS grant: 600-RMI/RAGS 5/3 (179/2012). Adibah Mohamad Daud, Nur Suria Abdul Ghafar, Nooramira Mohamad Kamis and Nurul Rafatin Rafiee Louis (HS2275, academic year 2014/15) who have assisted this study.

\section{References}

Azri, F. (2006). Migrasi Manusia Dari Sungai Mekong Ke Dunia Melayu Sejarah Melayu, Kisah Disebalik Nusantara (Vol. 2012). Malaysia: Woodpress.com.

Chenhall, C. (2011). Improving Cooking and Food Preparation Skills: A Synthesis of the Evidence to Inform Program and Policy Development (P.-C. P. H. Network, Trans.). Vancouver Canada: Public Health Agency of Canada.

Crouch, H. (1996). Government and Society in Malaysia. Sydney: Allen \& Unwin.

Guerrero, L., Guàrdia, M. D., Xicola, J., Verbeke, W., Vanhonacker, F., Zakowska-Biemans, S., . . Hersleth, M. (2009). Consumer-driven definition of traditional food products and innovation in traditional foods. A qualitative crosscultural study. [doi: DOI: 10.1016/j.appet.2008.11.008]. Appetite, 52(2), 345-354.

Gung-wu, W. (1985). Migration Patterns in History : Malaysia and the Region. Journal of the Malaysian Branch of the Royal Asiatic Society, 58(1).

Jaffar, J., Hussain, S., \& Ahmad, M. T. (1992). History of Modern Malay Literature. Kuala Lumpur: Dewan Bahasa dan Pustaka.

Kwik, J. C. (2008). Traditional food knowledge: A case study of an Immigrant Canadian "foodscape". Environments, 36(1), 59-74.

Md. Nor, N., Md. Sharif, M. S., Mohd. Zahari, M. S., Mohd. Salleh, H., Ishak, N., \& Muhammad, R. (2012). The Transmission Modes of Malay Traditional Food Knowledge within Generations. Procedia - Social and Behavioral Sciences, 50(0), 79-88. doi: 10.1016/j.sbspro.2012.08.017

Merriam, S. B. (2009). Qualitative Research: A Guide to Design and Implementation. San Francisco: Jossey-Bass.

Milburn, M. P. (2004). Indigenous Nutrition Using Traditional Food Knowledge to Solve Contemporary Health Problems. American Indian Quarterly, 28(3 \& 4).

Munan, H. (1990). Cultures of the World Malaysia. Singapore: Times Books International.

Ohiokpehai, O. (2003). Promoting the Nutritional Goodness of Traditional Food Products. Pakistan Journal of Nutrition, 2(4), 267-270.

Rahman, N. H. S. N. A. (2011). Malaysia, Brunei dan Selatan Thailand. In N. H. S. N. A. Rahman, Z. Ramli, M. Z. Musa \& A. Jusoh (Eds.), Alam Melayu: Satu Pengenalan (pp. 9). Bangi: Institut Alam dan Tamadun Melayu (ATMA). 
Sharif, M. S. M., Nor, N. M., \& Zahari, M. S. M. (2013). The Effects of Transmission of Malay Daily Food Knowledge on the Generation Practices. Procedia - Social and Behavioral Sciences, 85(0), 227-235. doi: http://dx.doi.org/10.1016/j.sbspro.2013.08.354

Sharif, M. S. M., Zahari, M. S. M., Nor, N. M., \& Muhammad, R. (2013). How could the Transfer of Food Knowledge be Passed down? Procedia - Social and Behavioral Sciences, 105(0), 429-437. doi: http://dx.doi.org/10.1016/j.sbspro.2013.11.045

Szulanski, G. (2000). The Process of Knowledge Transfer: A Diachronic Analysis of Stickiness. Organizational Behavior and Human Decision Processes, 82(1), 9-27. doi: 10.1006/obhd.2000.2884

Trichopoulou, A., Soukara, S., \& Vasilopoulou, E. (2007). Traditional Foods: A Science and Society Perspective. [doi: DOI: 10.1016/j.tifs.2007.03.007]. Trends in Food Science \& Technology, 18(8), $420-427$.

V.Kuhnlein, H., Donald, M. M., Spigelski, D., Vittrekwa, E., \& Erasmus, B. (2009). Gwich'in traditional food for health: Phase 1 Indigenous Peoples' food systems: the many dimensions of culture, diversity and environment for nutrition and health. Rome: Agriculture Organization of the United Nations.

Wilson, J., Ward, C., \& Fischer, R. (2013). Beyond Culture Learning Theory: What Can Personality Tell Us About Cultural Competence? Journal of Cross-Cultural Psychology, 44(6), 900-927. doi: 10.1177/0022022113492889

Yohannes, S. (2009). Traditional Food Consumption, Anthropometry. Nutrient Intake and the Emerging Relationship between Inuit Youth and Traditional Knowledge In Baffin Iskand Community. Montreal: McGill University. 